\title{
Effect of Processing Time on Recovery and Quality of Essential Oil from Patchouli (Pogostemon cablin Benth.)
}

\author{
D. Parganiha, S. Patel, C. K. Paikra and P. Sahu
}

Department of Agricultural Processing and Food Engineering, SVCAET \& RS, IGKV, Raipur, C.G. (492 012), India

\section{Corresponding Author}

D. Parganiha

e-mail: parganiha1708@gmail.com
Article History

Article ID: IJEP0235

Received in $26^{\text {th }}$ January, 2018

Received in revised form $10^{\text {th }}$ April, 2018

Accepted in final form $20^{\text {th }}$ April, 2018

\begin{abstract}
Patchouli (Pogostemon cablin) is fragrant herb produce essential oil, known as patchouli oil having high economic importance. Patchouli oil is widely used in food, pharmaceutical and cosmetic industries. Global demand is very high for Patchouli oil as compare to its production. Patchouli oil extraction is still new but has large market demand due to therapeutic and healing properties of oil. In this study an effort to increase the recovery of patchouli oil by standardizing the extraction process was performed. Drying of herbage before extraction was done in oven at $50^{\circ} \mathrm{C}$. Recovery of patchouli oil at different intervals of processing time viz., 4, 5, 6, 7 and 8 hours at $15 \%$ moisture was analyzed. It was observed that the oil recovery increased from 1.8 to $2.43 \%(\mathrm{w} / \mathrm{w})$ as processing time increased from 4 to 8 hours. The patchouli oil samples extracted during the study were also analyzed for its physico-chemical quality. All the extracted oil samples have shown the values of physico-chemical parametre in the satndard permissible range of patchouli oil except long extraction time (after 7 hours), due to which acid value of oil exceds the permissible limit. Hence, from the above work it may be concluded that the extraction of essential oil should be carried out at combination of $15 \%$ moisture $(\mathrm{db})$ and 7 hours of processing time intervals for better recovery and quality of oil.
\end{abstract}

Keywords: Distillation, essential oil, patchouli, recovery

\section{Introduction}

Patchouli (Pogostemon cablin), an essential oil bearing aromatic plant from family Lamiaceae. Commercial cultivation of the crop in India was first attempted by Tata Oil Mills in 1942. After initial stray attempts to grow the crop, its systematic cultivation started in 1962 by CIMAP (Gogoi, 2009). It is slowly spreading in the states of Karnataka, Gujarat, Assam, Andhra Pradesh, Kerala, Goa, Maharashtra, Madhya Pradesh and Orissa and is now becoming popular in Chhattisgarh. The dry leaves and stems of patchouli on steam distillation yield an essential oil. Patchoulol (Patchouli alcohol) is main component of oil. Patchouli oil is used in Food, Pharmaceutical and Cosmetic industries. The oil of patchouli is known to possess antifungal, antibacterial properties and is used in skin infections, dandruff and eczema, used as an ingredient in insect repellant preparations. The oil is also used in aromatherapy for its antidepressant, anti-inflammatory, cytophylactic and deodorant properties (Nasruddin et al., 2005). Indonesia is the major producer of patchouli oil in the world. Global demand for Patchouli oil is around 1,600 tons annum ${ }^{-1}$. Indian demand is around 220 t annum $^{-1}$ and production is very negligible. In the year 2009 and 2010, India imported the 57.42 t of oil of value 10.31 crores. Due to large gap between demand and supply, it is important to focus on the post harvest processing. Gap between production and demand can be reduced by standard extraction process.

There are several methods to extract the essential oil viz., steam distillation, supercritical solvent extraction; ultrasonic extraction and conventional distillation method etc. (Charles and Simon, 1990). Standard extraction process of essential oil play an important role in production. Extraction process for patchouli oil has not been standardized. Therefore, by considering the present need to provide the technology for processing of oil for improvement of oil recovery and its quality this research work has been done.

\section{Materials and Methods}

\subsection{Material collection}

Patchouli herbage was obtained from Herbal Garden, College of Agriculture, Raipur. The collected material had average moisture content in the range of $87-89 \%$. Whole patchouli plant (Leaves+Stems) was used for recovery of essential oil (Figure 1).

\subsection{Drying of patchouli herbage}

Oven drying at $50{ }^{\circ} \mathrm{C}$ for maintaining \% of moisture 
contents.
Percentage moisture content $(\mathrm{db})=\frac{W-w}{w} \times 100$

Where,

$W=$ Initial weight of sample, $g$

$\mathrm{w}=$ Final weight of sample after drying, $\mathrm{g}$

(Kongkathip et al., 2009)

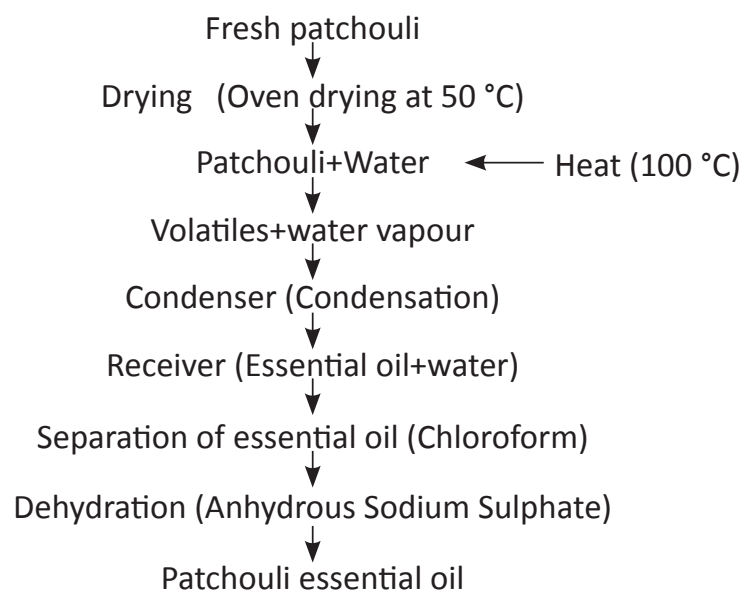

Figure 1: Flow diagram of patchouli oil extraction process

\subsection{Oil extraction}

Extraction of patchouli essential oil was done using Clevenger apparatus. Dried patchouli at $15 \%$ moisture was taken and subjected for oil extraction at different interval of time 4, 5, 6, 7 and 8 hours. Oil separation and dehydration was done using chloroform, separating funnel and anhydrous sodium sulfate.

\subsection{Quality analysis}

For quality analysis density, refractive index, acid value and ester value was calculated using standard methods. Statistical analysis technique was done using Completely Randomized Design (CRD), paired t-test to test the effect of processing time on recovery of patchouli oil (Steel and Torrie, 1981).

\section{Results and Discussion}

\subsection{Recovery of patchouli oil at different interval of processing time}

The graphical representation of the effect of different intervals of processing time on recovery of oil from patchouli is shown in Figure 2. The recovery of patchouli oil determined were 1.8 to $2.43 \%(\mathrm{w} / \mathrm{w})$. Four hour processing time gives least recovery $(1.8 \%)$ and 8 hour processing time gives highest recovery of patchouli oil (2.43\%). It was observed that as the processing time increases, the recovery of patchouli oil also increases. Effect of processing time on recovery of oil from patchouli was also analyzed statistically. Statistical analysis of data $\left(C_{p=0.05}=\right.$ 0.13 ) clearly indicates that there is significant change in recovery of patchouli oil in respect of processing time.

3.2. Physico-chemical quality of patchouli oil extracted at different interval of processing time

Density, refractive index, acid value and ester value of patchouli oil were represented by the Figure 3. It was observed that the density of patchouli oil increases from 0.955 to 1.0 $\mathrm{g} \mathrm{ml}^{-1}$. Refractive index of different extracts decreases from 1.5124 to 1.5021 . Acid value of different extracts increases gradually from 1.68 to 5.05 . Ester value of different extracts decreases gradually from 7.85 to 5.61 . All the extracted oil samples have shown the values of physico-chemical parametre in the satndard permissible range of patchouli oil except long extraction time (after 7 hours), due to which acid value of oil exceds the permissible limit.

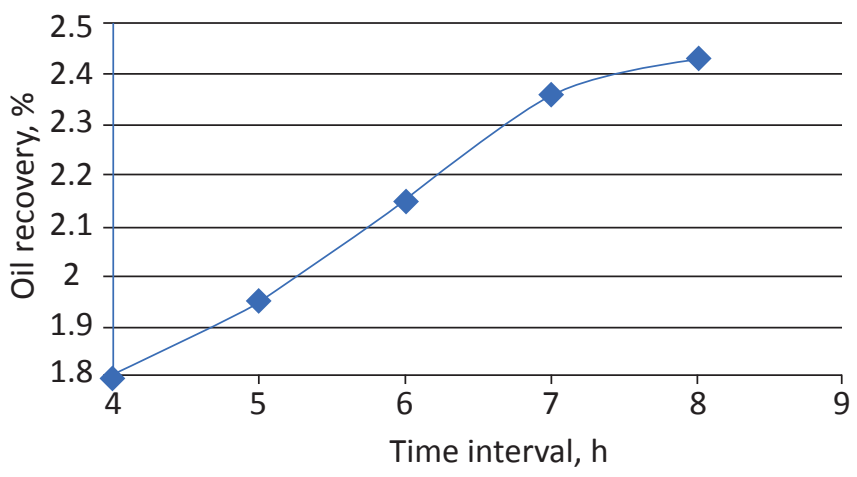

Figure 2: Oil recovery at different time interval of processing

Density $\left(\mathrm{g} \mathrm{ml}^{-1}\right)$ Refractive index $\square$ Acid value

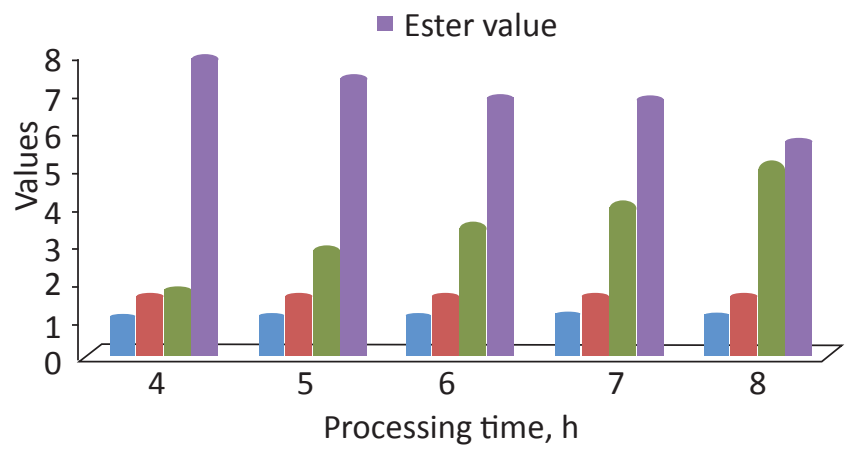

Figure 3: Physico-chemical quality of patchouli oil extracted at different interval of processing time

\section{Conclusion}

Oil recovery sharply increased as the processing time increased up to 7 hours. However, maximum recovery $(2.43 \%)$ was observed at 8 hours. All the extracted oil samples have shown the values of physico-chemical parametre in the satndard permissible range of patchouli oil except long extraction time (after 7 hours), due to which acid value of oil exceds the permissible limit. Hence, from the above work it may be concluded that the extraction of essential oil should be carried out at combination of $15 \%$ moisture $(\mathrm{db})$ and 7 hours of processing time intervals for better recovery and quality of oil.

\section{References}

Charles, D.J., Simon, J.E., 1990. Comparison of extraction methods for the rapid determination of essential oil 
content and composition of basil. Journal American Society Horticulture Science 115(3), 458-462.

Gogoi, P.B., 2009. Economic feasibility of patchouli cultivation in Assam. Indian Journal of Arecanut, Spices and Medicinal Plants 11(3), 100-106.

Kongkathip, N., Samang, P., Kongkathip, B., Pankaew, Y., Tanasombat, M., Udomkusonsri, P., 2009. Development of patchouli extraction with quality control and isolation of active compounds with antibacterial activity. Kasetsart Journal of Natural Sciences 43, 519-525.

Nasruddin., Gatot, P., Basuni, H., 2005. Study on distillation process of patchouli oil through leaves delignification. Journal Teknologi Dan Industri Pangan 16(3), 243-247.

Steel, G.D., Torrie, H.J., 1981. Principle and procedures of statistics-a biometrical approach, $2^{\text {nd }}$ (Ed.), McGraw- Hill, Inc. Singapore. 